The Dhaka University Journal of Linguistics: Vol. 2 No.3 February, 2009 Page: 111-124, Published on December 2009 by the Registrar, Dhaka University ISSN-2075-3098

\title{
Semiotic Interpretation of Bangla Ligatures: An Introduction
}

\begin{abstract}
Sanjida Afrin ${ }^{1}$
1. M. Phil Researcher, Department of Linguistics, University of Dhaka.

Abstract

Semiotics is the study of sign processes emphasizing signification and communication, signs and symbols of different social phenomena. In the late $19^{\text {th }}$ and early $20^{\text {th }}$ century the works of Ferdinand de Saussure and Charles Sanders Peirce led to the emergence of semiotics as a separate discipline as well as method for examining phenomena in different fields, including aesthetics, anthropology, communications, psychology, and semantics. Saussure's interpretation of linguistic sign from a semiotic perspective has, better or worse, affected much of subsequent discussions about language. But according to Peirce, meaning is not directly attached to the sign; instead, it is mediated through the interaction between the representamen, interpretant, and object. This paper initiates $a$ brief semiotic interpretation of Bengali ligature-an essential component of Bengali writing system, since semiotics considers ligature, like other linguistic components, a potential sign-unit.
\end{abstract}

Key words : ligature, Saussure, Peirce, Object.

\section{Introduction}

Semiotics is an enormously broad approach to understand verbal and non-verbal meaning as well as cognition, culture, behavior, even life itself. In semiotics everything is considered

The Dhaka University Journal of Linguistics sign, as the notion 'sign' lies at the heart of this discipline. 'Sign are found in the physical form of words, image, sounds, acts or objects .... Signs things have no intrinsic meaning and become signs only when we invest them with meaning with reference to a recognized code'. (Chandler, 2002: 241). Anything can be a sign as long as someone interprets it as 'signifying' something - referring to or standing for something other than itself. We interpret things as signs largely unconsciously by relating them to familiar systems of conventions.

In the writing system, alphabets are also signs and therefore we can assume that they can be interpreted by semiotics. This broad hypothesis has led us to analyze the structure of Bangla ligatures in the light of this discipline, since it is well known that one of the distinctive components of Bangla writing system is ligature. In writing and typography, a ligature occurs where two or more letterforms are written or printed as a unit. In other words, ligature is a combination of two or more letters to form a single sign. Generally, ligatures replaced characters that occur next to each other when they share common components. In this paper, we present a brief introduction to Bangla ligatures from the perspective of semiotics.

\section{A brief semiotic Interpretation of Bangla ligatures \\ 2.1 Bengali ligatures}

'In Indian writing system, ligatures play an important role as the common means of representing $\mathrm{C}$ (consonant) clusters' (Coulmas, 1999 : 295). Since Bengali (Bangla) writing system derives from Indian origin Brahmi script, ligatures play a very significant role. They are typically formed by conjoining parts of two or more $\mathrm{C}+\alpha$ letters to form a distinct grapheme for a complex syllable. These elements are conjoined horizontally or vertically. Since the composition of many ligatures is no longer self-evident, they have to be learned separately in addition to the basic letters. In handwriting, the shapes of the conjoint Vol. 2 No.3 February, 2009 
letters vary from person to person. But the shape and structure of the ligatures in typography is fixed. Conjoint letter is a term used in the analysis of the connection of speech to refer any sequence of adjacent consonants occurring initially, medially or finally in a syllable.

\subsubsection{Structure of Bengali conjoint letter}

Structurally there are three kinds of conjoint letters in Bangla. These are as follows.

Bi-consonantal conjoint: When conjoint letters are formed by two consonants, as -

\begin{tabular}{|l|}
\hline $\mathbf{i} \rightarrow \mathbf{j}+\mathrm{c}=\mathrm{Ki}$ \\
\hline $\mathrm{o} \rightarrow \mathrm{i}+\mathrm{U}=\mathrm{Kó}$ \\
$\mathrm{c} \longrightarrow \mathrm{c}+\mathrm{j}=\mathrm{k} \boldsymbol{\sigma}$ \\
\hline
\end{tabular}

Tri-consonantal conjoint: When conjoint letters are formed by three consonants, as-

$$
\begin{array}{|c|}
\hline \check{s} z=b+z+i \rightarrow h^{h} z \\
\hline-z=m+z+i \rightarrow{ }^{-} x \\
\hline
\end{array}
$$

Poly-consonantal conjoint: When conjoint letters are formed by four or more consonants, as -

$$
\check{s} \ddot{z}=b+z+i \quad+h \rightarrow-\nabla \check{z} \ddot{z}
$$

\subsubsection{Shape of the conjoint letters}

Concerning the shape of the grapheme used in conjoint letter, it consists of two types:

Horizontal conjoint letters: Two or more consonant letters are conjoint horizontally. As in-

\begin{tabular}{|c|}
\hline $\bar{y}=n+b \rightarrow$ Avgr $K$ \\
\hline$n \ddot{Y}=n+e \rightarrow$ Avn̈̈b \\
\hline$\mu=K+i \rightarrow$ P \\
\hline
\end{tabular}

The Dhaka University Journal of Linguistics
Vertical conjoint letters: Two or more consonant letters are conjoint vertically. As in -

\begin{tabular}{|l|}
\hline$K_{i}=K+e \rightarrow c K_{i}$ \\
\hline$Z o e Z+b \rightarrow i Z o e$ \\
\hline$a \simeq g+e \rightarrow j$ sa \\
\hline$b o e b+b \rightarrow$ bevboe \\
\hline
\end{tabular}

New graphical forms of conjoint letters can be shaped by conjoining two or

\begin{tabular}{|c|}
\hline$\eta=\mathrm{K}+\mathrm{I} \rightarrow \mathrm{A} \eta \mathrm{i}$ \\
\hline$p=n+g \rightarrow$ epo \\
\hline$,=M+D \rightarrow, g$ \\
\hline$\ddot{E}=z+z \rightarrow g \ddot{E}$ \\
\hline A $=R+T \rightarrow$ D \\
\hline$\eta \grave{e}=K+I+Y \rightarrow Z$ Zlè \\
\hline
\end{tabular}
more consonants. As in -

\subsubsection{Usages of Conjoint Letters}

Bangla script uses different conjoint letters. Some of them are as follows:

Conjoining by two different letters:

\begin{tabular}{|c|}
\hline$-u=m+c \rightarrow-{ }^{\prime} \mathrm{b}$ \\
\hline$>^{\prime}=\mathrm{b}+{ }^{-} \rightarrow \mathrm{b}^{\prime} \mathrm{b}$ \\
\hline $3=\mathrm{K}+\mathrm{Z} \rightarrow \mathrm{h}$
\end{tabular}

\begin{tabular}{|c|}
\hline $\mathbf{j}=\mathbf{j}+\mathbf{j} \rightarrow$ K业 $\mathbf{\Psi}$ \\
\hline$\overline{\mathrm{I}}=+^{-} \rightarrow$ ei $\ddot{v}$ \\
\hline$A E=U+U \rightarrow$ AAgivKV \\
\hline$' P=P+P \longrightarrow D P$ \\
\hline
\end{tabular}

Conjoining by same letters:

\subsubsection{Position of the Conjoint Letters in a Morpheme}

Vol. 2 No.3 February, 2009 
In Bangla script conjoint letter used in three positions -

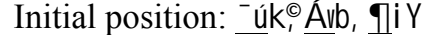

Medial position: A- bi-b, AK

Final position: ‘

\subsubsection{Shape of the Graphemes Used in Conjoint Letter}

The grapheme used in conjoint letter may change their original shape. As -

The former letter or grapheme is big and the later grapheme is small. As -

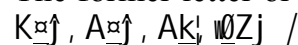

The later grapheme is big and the former grapheme is small. As KE k니

Both are same in size. As $-\mathrm{j}$ 3/4 trôpir, DÇ abl

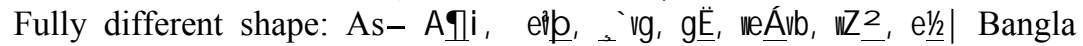
ligatures are the graphical representation of Bangla conjoint letters; unlike English the single vowel graphemes and consonant graphemes are commonly attached together in this writing system. However, we delimit our discussion within the consonantal attachments.

\subsection{Sign System}

As we saw earlier, semiotics is the scientific study of signs and sign-functions. 'Semiotics is concerned with everything that can be taken as a sign' (Eco, 1976 : 7). For semiotic interpretation of Bangla ligatures, it is necessary to know the major theories of the proponents of Semiotics, specially the concept of Saussure and Peirce.

\subsubsection{Semiotics and Ligature according to Saussure}

Ferdinand de Saussure has been called 'the father of modern linguistics'. Being the founder of both modern linguistics and semiotics, Saussure's elaboration of the linguistic sign from a semiotic perspective has, for better or worse, affected much of subsequent discussions about language. Saussure offered a 'dyadic' or two-part model of the sign. He defined a sign as being composed of:

signifier- the form which the sign takes;

signified - the concept it represents.

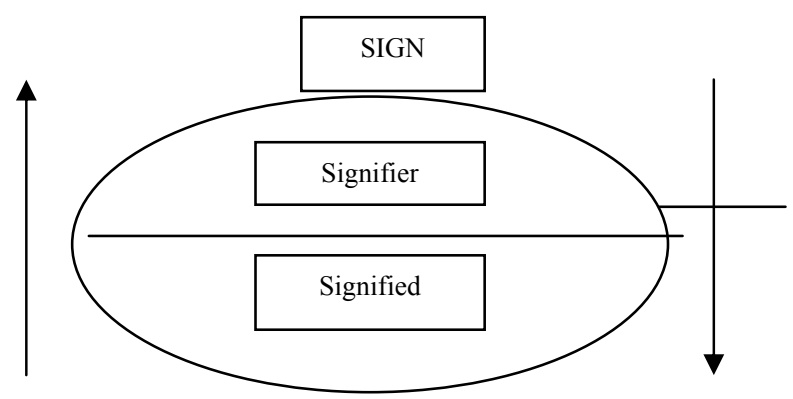

Figure: 1 Signifier and Signified

Saussure makes the distinction of these terms:

'A linguistic sign is not a link between a think and a name, but between a concept [signified] and a sound pattern [signifier]. The sound pattern is not actually a sound; for a sound is something physical.' (Saussure, 1983, 66)'

For an example, in the word 9 gr[khoma], ' $q$ ' is a ligature as well as a sign. The signified of the sign ' $q$ ' is its physical existence. The signifier of it is $\mathrm{K} / \mathrm{k} /$ and $1 / \mathrm{s} /$ being together and formed a compact grapheme or ligature $\pi$.

The sign, as union of a signifier and a signified, has two main characteristic. The bond between the signifier and signified is arbitrary. This principle dominates all ideas about the structure of language. It makes it possible to separate the signifier and signified, or to change the relation between them. (This makes possible the idea of a single signifier, which could be associated with more than one signified, or vice-versa, which makes ambiguity and multiplicity of meaning possible (Lyons, 1977-71).

Language is only one type of semiotic system. Any system of signs, made up of signifiers and signified, is a semiotic or signifying system. There may be some kinds of signs that seem less arbitrary than others. Saussure discusses whether symbols, such as the use of scales for the idea of justice, are natural or 
arbitrary, and decides that these too are arbitrary, or based on society agreement.

The sign is the whole that results from the association of the signifier with the signified (Saussure, $1974: 67$ ). The relationship between the signifier and the signified is referred to as 'signification', and this is represented in the Saussurean diagram shown in figure 2 by the arrows. The horizontal line marking the two elements of the sign is referred to as 'the bar'.

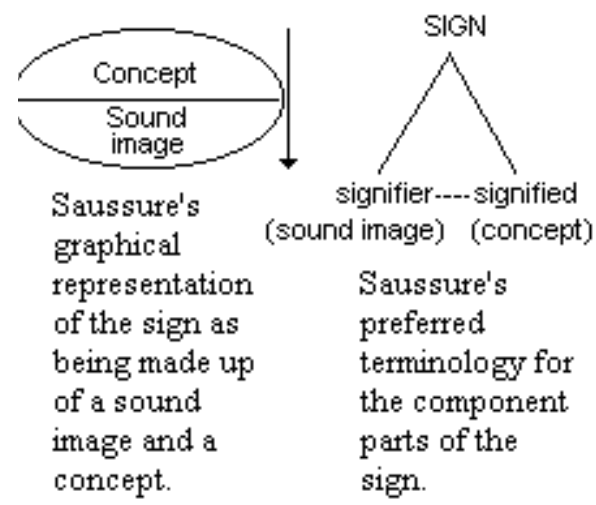

Figure 2: Saussurean Dyadic Model of Sign

We take a ligature as an example of Saussurean sign in the word '

a signifier: The ligature 'in the word

a signified: that the ligature 'is made by connecting the letters of $g / m /, f$ $\mathrm{b}^{\mathrm{h}} /$ and $\mathrm{i} / \mathrm{r} / \mathrm{and}$ created the new glyph

A sign must have both a signifier and a signified. It is also a recognizable combination of a signifier with a particular signified.

\subsubsection{Signification}

In Saussurean semiotics, the term 'signification' refers to the relationship between the signifier and the signified. 'The signification can be conceived as a process; it is the act which

The Dhaka University Journal of Linguistics binds the signifier and signified, an act whose product is the sign.'(Roland Barthes, 1964, 48). Signification is variously used to refer to -

1. The signifying function of the sign;

2. The process of signifying;

3. Signs as part of an overall semiotic system;

4. What is signified;

5. The representation;

6 . The reference of language to reality.

\subsubsection{Value}

According to Saussure, the value of a sign depends on its relations with other signs within the system - a sign has no 'absolute' value independent of this context. Saussure uses an analogy with the game of chess, noting that the value of each piece depends on its position on the chessboard (Chandler, 2002 : 246).

\subsubsection{The principle of Arbitrariness}

Sausserean semioticians emphasize that there is no necessary, intrinsic, direct or inevitable relationship between the signifier and the signified. The link between the 'signifier and signified' is arbitrary (Saussure, 1983, 115).

The principle of arbitrariness can be applied not only to the individual sign, but also to the whole sign-system. The term signification arises from the Saussurean concept of the sign where by the sign is seen as a binary entity comprising-

Signifier $\rightarrow$ The form which the sign takes

Signified $\rightarrow$ The concept it represents

2.2.5 Syntagmatic and paradigmatic relation

Saussure emphasizes that a sign gains its value from the difference between the signified and the signifier, and these differences are of two kinds-

1. syntagmatic

2. paradigmatic

These two dimensions are often presented as 'axes' where they correspond to two forms of mutual activity:

Vol. 2 No. 3 February, 2009 
Axis of combination- horizontal axis (Syntagmatic axis) Axis of selection- vertical axis (Paradigmatic axis)

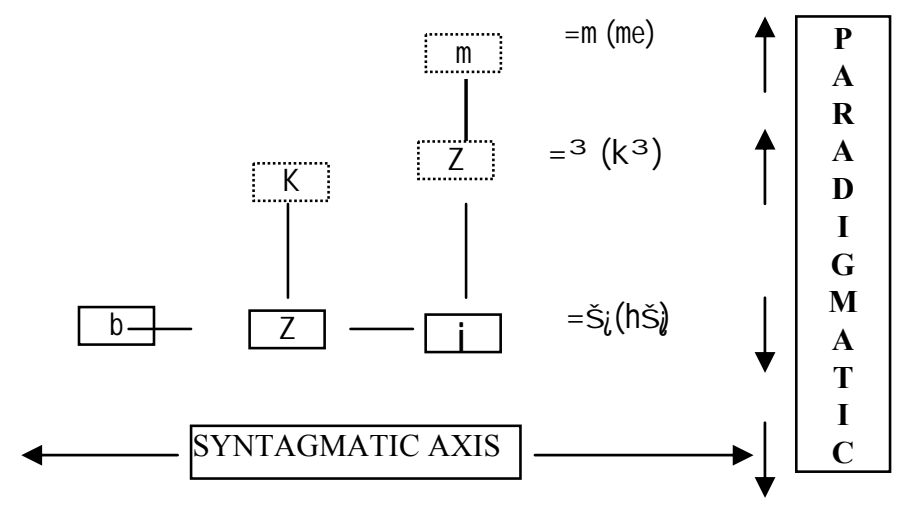

Figure 3: Syntagmatic and paradigmatic relation

\subsubsection{Axis of combination}

Textual analysis based on this axis is called Syntagmatic analysis. Syntagmatic analysis is a structuralist technique which seeks to establish the 'surface structure' of a text and the relationship between its parts (Saussure, 1983, 121). It involves the following two concepts-

a. syntagm

b. syntagmatic relation

a. Syntagm- This is a very useful insight in the analysis of signs. Language is linear. We produce one sound after another; words follow one another. When we think of signs interlinked in this way (for example, in language, coming one after

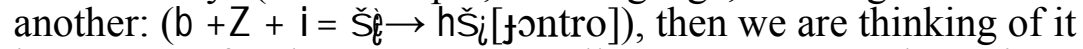
in terms of what Saussure calls a syntagm. There is a syntagmatic relationship between them.

b. Syntagmatic relations- Syntagmatic relations are the various ways in which constituent units within the same text may be structurally related to each other. A signifier enters into syntagmatic relations with other signifiers of same structural level within the same text (Chandler, 2002 : 81). Syntagmatic relationship exists-

The Dhaka University Journal of Linguistics between signifiers;

between signifieds.

Based on this, syntagmatic relations are of the following three types-

Relationships between signifiers: Sequential and Spatial

Relationships between signified: Conceptual

i. Sequential - sequential relationships are based on sequences of syntagms best exemplified by narratives (Chandler, 2002, 83). As in the word $K i$ [kolpo], M [golpo], the ligature is í odhe sequential relation of the ligature is j...c. Again in the word w relation of the ligature is c...U.

ii. Spatial- Spatial relationships work through the juxtapositions of constituents. The spatial relation of the

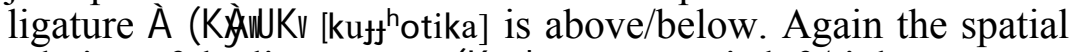
relation of the ligature, aú (Kaúb [kompon]) is left/right.

iii. Conceptual- conceptual relations rely on the conceptual structure of argument of description as found in exposition. Exposition relies on the conceptual structure of argument or description. (Chandler, 2002 : 84). It involves three basic elements:

a proposition or series of propositions evidence justifications.

In the Bangla word exor [brahmon], $\mathrm{p}$ is an important ligature. This ligature is formed by conjoining $\mathrm{n} / \mathrm{h} /$ and $\mathrm{g} / \mathrm{m} /$. When these two letters are attached together, they produce a new glyph. As being a Bangla language speaker, we know that $n$ and $\mathrm{g}$ are connected to each other and made a glyph $\mathrm{p}$.

2.2.5.2 Axis of Selection

A textual analysis based on this vertical is called a paradigmatic analysis. A paradigmatic analysis seeks to identify the various paradigms which underlie the manifest content of texts. This analysis involves a consideration of the positive or negative connotations of each signifier and the existence of 'underlying' thematic paradigms (ibid.,80).

Hence a paradigmatic analysis involves the following two-

a. paradigms

b. paradigmatic relations 
a. Paradigms- a paradigm is a set of associated signifiers or signifieds which are all members of some defining category, but in which each is significantly different.

b. Paradigmatic relations- Paradigmatic relations are the oppositions and contrasts between the signifiers that belong to the same paradigm set. Paradigmatic relations are associative or contrastive relationships based on choice. Here the coordinations are outside discourse and are not supported by linearity. They are vertical type of relations. The following chart is an example of paradigms and paradigmatic relations (ibid.,83).

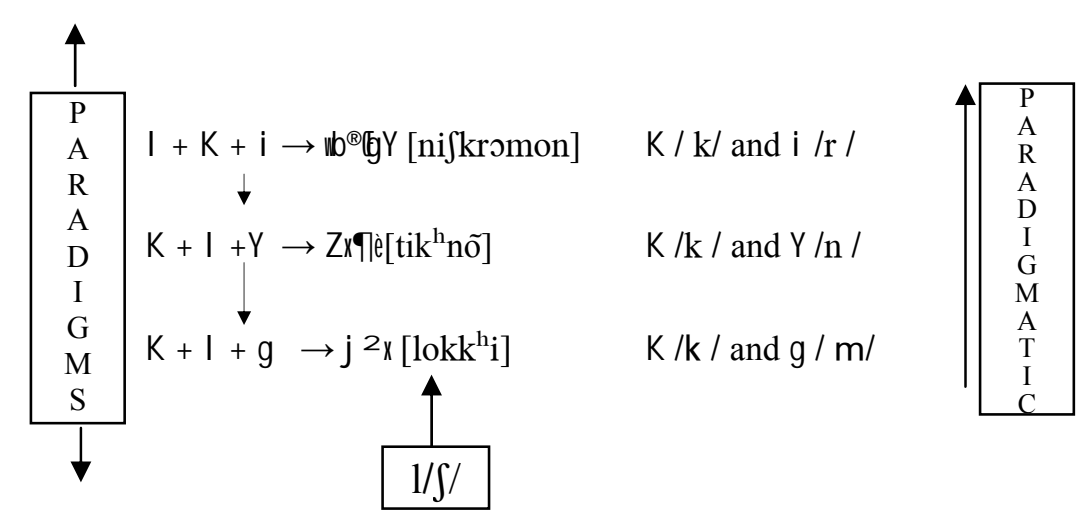

Figure: 4 Paradigm and Paradigmatic Relation

\subsection{Semiotics and Ligature according to Peirce}

Charles Sanders Peirce (1839-1914) was an American philosopher, logician, and scientist. Peirce presented a triadic model of the sign as opposed to Saussure's dyadic model of signified and signifier. The model has three parts-

2.3.1 A Representamen: Representamen is the (not necessarily physical) form of sign. It is that character of a thing which produces a certain mental effect. It is the form of a sign, not necessarily physical. A sign is a representamen with a mental Interpretant.
2.3.2 An Interpretant: An interpretant is a sense made of the sign in the mind of the observer. The interpretant is a momentary result of sign interpretation. The interpretant is the interpreting thought, action or experience. How signs represent their objects is revealed by their interpretants.

2.3.3 An Object: An Object is anything that we can think of, talk about. It may have a physical existence.

The object is divided into-

- The Immediate Object- the object as represented in the sign.

- The Dynamical Object- which, from the nature of things, the sign cannot express, and which it can only indicate and leave the interpreter to find out by a collateral experience.

Thus, according to Peirce-

A sign... [In the form of a representamen] is something which stands to somebody for something in some respect or capacity. In address to somebody, that is, creates in the mind of that person an equivalent sign, or perhaps a more develop sign. That sign which it creates I call the interpretant of the first sign. The sign stands for something, its object. It stands for the object, not in all respects, but in reference to a sort of idea, which I have sometimes called the ground of representamen. (Peirce 1931-58, 2.228)

These three parts are together known as the 'semiotic triad', and together they form a sign. As mentioned before, meaning is not directly attached to the sign; instead, it is mediated through the interaction between a representamen, an interpretant, and an object. Peirce referred to this as the process of 'semiosis'. The figure in the following displays these relationships (the dashed line represents the indirect path between a representamen and an object. 


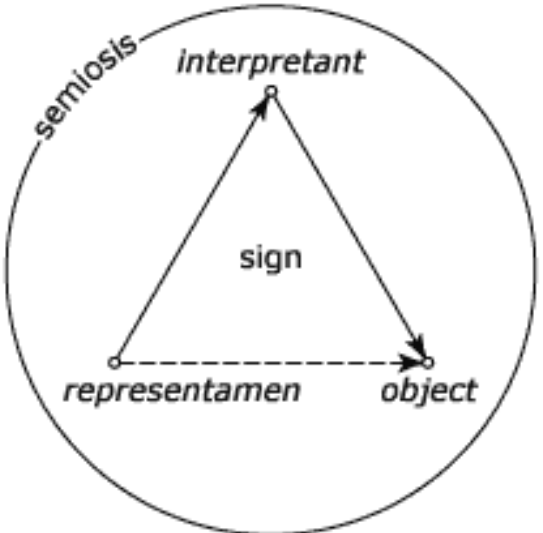

Figure 5: Peircean Triadic Model of Sign

For an example ' $q$ ' is a ligature in the word $9 \mathrm{gv}\left[\mathrm{k}^{\mathrm{h}}\right.$ oma $]$. It consists of two different letters, $\mathrm{k} / \mathrm{k} /$ and $~ / \int /$. So the object of the ligature is the physical appearance of $\pi$. The interpretant or impression is the mental activity that $\mathrm{k} / \mathrm{k} /$ and $\mathrm{I} / \mathrm{f}$ / produce a ligature. By this ligature many words can be formed, as $q_{1} \mathrm{Y}$, $f$ m $r$ etc. The representamen or referent is the mental existence of the ligature ฯ. It has no any physical existence. This ligature is formed by joining the mental image of the sound $\mathrm{k}+\int$. This process is shown in figure 6 .

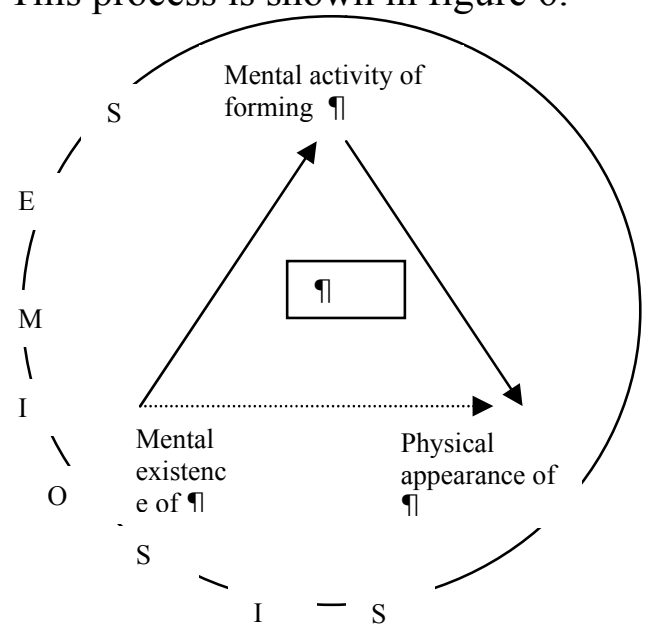

Figure 6: Ligature in Semiotic Tried

The Dhaka University Journal of Linguistics

\section{Conclusion:}

Like all other writing systems derived from Brahmi tradition, Bangla ligature also maintain multi-dimensional semiotic value. A lot of interchanges are also occurred within their mutual correspondence. Therefore, Bangla ligature can be treated as the spacious field for semiotic interpretation. Bangla words and their meaning can be influenced by the proper uses of ligatures. Moreover, sometimes the Bangla acronyms even the mental states of individuals are also associated with proper uses of ligatures. So, concerning written communication of Bangla, ligatures play a very significant role. The theory of semiotics mainly analyze these significations. Some aspects of these kinds of significations have been analyzed. Nevertheless semiotic interpretation is always related to the contexts and culture. Consequently, in course of time, the cultural aspects of society and their contextual state are an ever-changing phenomenon. So, these semiotic interpretations of Bangla ligature can be modified yet changed in different context and culture. Whatever, it will happen, the main objective is that, Bangla ligature is a great source of semiotic interpretation.

On the other hand, Bangla ligature and their multi dimensional approaches is an interesting field of semiotic research.

\section{Reference}

Barthes, Roland. 1964. Elements of Semiology. New York: Hill and Wang. Chandler, Daniel. 2002. Semiotics: the Basics. London: Routledge.

Coulmas, Florian 1999. The Blackwell Encyclopedia of Writing Systems. Massachusetts: Blakwell Publishers.

Crystal, David. 1885. The Cambridge Encyclopedia of Language. Cambridge: Cambridge University Press.

Eco, Umberto 1976. A Theory of Semiotics IN: Bloomington: Indiana University Press

Lyons, John. 1977. Semantics, vol. 1. Cambridge: Cambridge University Press.

Pierce, Charles Sander (1931-58). Collected Writings. (8 Vols). Charles Hartshorne, Paul Weiss and Arthur W. Burks (eds.). Cambridge, MA Harvard University Press

Saussure, Ferdinand de. 1916[1974]. Course in General Linguistics. [trans. Wade Baskin]. London: Fontana/Collins

Saussure, Ferdinand de. 1916[1983]. Course in General Linguistics. [trans. Roy Harris]. London: Duckworth.

Email Contact: synthi_15@yahoo.com 
